\title{
Simulation and Design of InGaAsN-based Heterojunction Bipolar Transistors for Complementary Low-Power Applications
}

C. Monier ${ }^{a)^{*}}$, P. C. Chang ${ }^{b)}$, N. Y. Li ${ }^{c)}$, J. R. LaRoche ${ }^{d)}$, A. G. Baca ${ }^{b)}$, H. Q. Hou ${ }^{c)}$, F. Ren ${ }^{d)}$, and S. J. Pearton ${ }^{a)}$

a): Department of Materials Science and Engineering, University of Florida, Gainesville, Florida 32611

b): Sandia National Laboratories, Albuquerque, New Mexico 87185

c): Emcore Photovoltaics, Emcore Corporation, Albuquerque, New Mexico 87123

d): Department of Chemical Engineering, University of Florida, Gainesville, Florida 32611

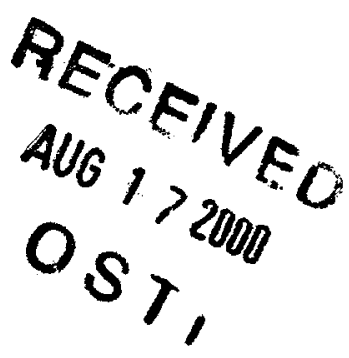

* Corresponding author. Current address at Sandia National Laboratories. Tel.: +1 (505) 284-

4120; fax: +1 (505) 844-8985; E-mail address: cmonier@sandia.gov (C. Monier).

\section{Abstract}

The performance capabilities of $P_{n p}$ InGaAsN-based heterojunction bipolar transistors (HBT) for use in complementary HBT technology have been theoretically addressed with a twodimensional simulation program based on the drift-diffusion model. Simulation results closely reproduce the DC characteristics experimentally observed from the first demonstrated $P n p$ AlGaAs/InGaAsN HBT with a current gain of 18 and a turn-on voltage around $0.89 \mathrm{~V}$. Numerous design approaches have been explored to maximize the transistor performances. As a result, a substantial improvement of the DC current gain (by a factor of 2-3) and high-frequency operation performances (with $f_{T}$ and $f_{M A X}$ values up to $10 \mathrm{GHz}$ ) can be easily achieved with the proper use of varying base thickness $X_{B}$ and dopant-graded base. The effect of the quaternary band-gap $\mathrm{E}_{\mathrm{G}}$ value is also addressed. Simulation results show that Pnp device with turn-on 
voltage $\sim 0.7 \mathrm{~V}$ can be produced by lowering $\mathrm{E}_{\mathrm{G}}$ to $1.0 \mathrm{eV}$, without any important degradation of DC and r.f. properties, because hole transport at the emitter/base side is not strongly affected. The replacement of the InGaAsN collector by GaAs is finally reported. Comparable DC and improved r.f. simulated performances are observed from this double HBT structure that takes advantages of the negligible Valence Band offset at the base/collector interface. These encouraging performances demonstrate the practicability of using InGaAsN-based HBTs for complementary low-power applications.

Keywords: AlGaAs/InGaAsN, Heterojunction Bipolar transistor, two-dimensional (2D) simulation, Pnp configuration, DC current gain, Dopant-graded doping, Turn-on voltage, High frequency characteristics. 


\section{DISCLAIMER}

This report was prepared as an account of work sponsored by an agency of the United States Government. Neither the United States Government nor any agency thereof, nor any of their employees, make any warranty, express or implied, or assumes any legal liability or responsibility for the accuracy, completeness, or usefulness of any information, apparatus, product, or process disclosed, or represents that its use would not infringe privately owned rights. Reference herein to any specific commercial product, process, or service by trade name, trademark, manufacturer, or otherwise does not necessarily constitute or imply its endorsement, recommendation, or favoring by the United States Government or any agency thereof. The views and opinions of authors expressed herein do not necessarily state or reflect those of the United States Government or any agency thereof. 


\section{DISCLAIMER}

Portions of this document may be illegible in electronic image products. Images are produced from the best available original document. 


\section{Introduction}

The InGaAsN alloy system is currently attracting a significant attention due to its potential application for optoelectronic devices [1,2]. The introduction of nitrogen into InGaAs strongly reduces its band-gap, mainly by an increase of the conduction band offset and makes the InGaAsN alloy attractive for optical-fiber communications [3-5]. The use of the GaAs-lattice matched quaternary material might turn as well into a suitable approach for the realization of low-power electronic devices. The Heterojunction Bipolar Transistor (HBT) technology with the InP/InGaAs material system has demonstrated good potential for this application [6] with the use of a small band-gap material in the base for an advantageous lower turn-on voltage $V_{O N}$ but the high-cost InP technology has limited its commercial application. Progress in (In,Ga)(As,N) material quality has motivated the development of new bipolar transistors using this alloy as the base and collector layers to produce cost-effective low power electronic devices for GaAs substrates.

One report has recently appeared on operation of $N p n \operatorname{InGaP} / \mathrm{InGaAsN} / \mathrm{GaAs}$ double HBTs with the InGaAsN band-gap $E_{\mathrm{G}}=1.2 \mathrm{eV}$ [7]. Initial performances are comparable with the conventional InGaP/GaAs counterpart and a reasonable reduction of $\mathrm{V}_{\mathrm{ON}}(0.88 \mathrm{~V}$ instead of 1.05 V) is observed. In addition to Npn HBTs, the development of Pnp InGaAsN-based HBT is of fundamental interest for use in complementary HBT technology, for enhanced high-frequency integrated circuits used for digital, linear and microwave applications [8,9]. Excellent characteristics are required for both devices, especially on the Pnp side that often limits performances of the monolithically integrated transistor. Preliminary results on InGaAsN Pnp's exhibit current gain values that have reached useful level [10] but would require improvement. 
While modeling of HBT performance has been ongoing in InP/InGaAs, AlGaAs/GaAs or GaN-based systems [11-13], there has been no attempt at simulating HBT's in this pioneering material. In this work, we report on the simulation results of the InGaAsN-based HBTs with an emphasis on the challenging Pnp for use in assessing the factors maximizing device performances and in providing trends for the epitaxial multilayer structure to further extend the effectiveness of complementary HBT technology. The paper is organized as follows. Preliminary experimental results on Pnp AlGaAs/InGaAsN HBTs are first detailed as well as the $\mathrm{AlGaAs} / \mathrm{GaAs}$ structure that serves as reference. The simulation approach is first employed to reproduce the initial experimental observations. Different design approaches are considered to optimize DC and r.f. performances and further lower the turn-on voltage of the InGaAsN-based device. Predicted performances of a double heterostructure AlGaAs/InGaAsN/GaAs HBT structure are finally compared with the device using a single heterostructure.

\section{$\underline{\text { 2. Preliminary experimental results }}$}

The pioneering experimental work consists of investigating the influence of a quaternary InGaAsN material replacing the conventional binary GaAs material used for the base and the collector of a Pnp AlGaAs/GaAs HBT. As N is incorporated into GaAs, a tensile strain develops, and both the conduction band $\left(\mathrm{E}_{\mathrm{C}}\right)$ and the valence band $\left(\mathrm{E}_{\mathrm{V}}\right)$ are lowered. On the other hand, a compressive strain builds up as Indium is added to $\mathrm{GaAs}$, and $\mathrm{E}_{\mathrm{G}}$ is reduced, the $\mathrm{E}_{\mathrm{C}}$ is lowered and the $\mathrm{E}_{\mathrm{V}}$ is raised. By incorporating the proper amount of In and $\mathrm{N}$ into GaAs simultaneously, InGaAsN that is lattice matched to GaAs can be obtained [14]. The $\mathrm{E}_{\mathrm{C}}$ of the resulting InGaAsN would be much lower because of the aggregate lowering effect from the incorporation of $\mathrm{N}$ and In. The energy level of $E_{V}$ would depend on the amount of nitrogen incorporation, and for $\mathrm{In}_{0.03} \mathrm{Ga}_{0.97} \mathrm{As}_{0.99} \mathrm{~N}_{0.01}$, the effects on $\mathrm{E}_{\mathrm{V}}$ from incorporation of nitrogen and In are compensated, 
and the $E_{V}$ is relatively unchanged compared to the $E_{V}$ level of GaAs. The resulting band alignment is shown in Fig. 1 along with the conventional AlGaAs/GaAs system. According to Kondow et al. [14], a conduction band offset ratio of $Q_{C}=0.75$ is used to describe the distribution of the band-gap energy difference between $\mathrm{Al}_{0.30} \mathrm{Ga}_{0.70} \mathrm{As}$ and $\mathrm{In}_{0.03} \mathrm{Ga}_{0.97} \mathrm{As}_{0.99} \mathrm{~N}_{0.01}$ (with $\mathrm{E}_{\mathrm{G}}=1.2$ eV). This band alignment is more favorable for the Pnp InGaAsN-based HBT structure than the $Q_{C}$ value of 0.66 classically reported for the $\mathrm{Al}_{x} \mathrm{Ga}_{1-x} \mathrm{As} / \mathrm{GaAs}$ system. This large conductionband discontinuity $\left(\Delta \mathrm{E}_{\mathrm{C}} \sim 0.5 \mathrm{eV}\right)$ will substantially reduce the amount of minority electrons to be back injected into the emitter while the small Valence-band discontinuity $\left(\Delta \mathrm{E}_{\mathrm{V}} \sim 0.15 \mathrm{eV}\right)$ is advantageous for a more efficient hole transport from the emitter to the base.

An initial AlGaAs/GaAs structure serving as reference was grown and defined by a 0.5 $\mu \mathrm{m}$, Carbon-doped $\left(3 \times 10^{16} \mathrm{~cm}^{-3}\right) \mathrm{GaAs}$ collector followed by a $0.1 \mu \mathrm{m}$, Silicon-doped with a doping concentration of $3 \times 10^{18} \mathrm{~cm}^{-3} \mathrm{GaAs}$ base and a $0.1 \mu \mathrm{m}$, Carbon-doped $\left(3 \times 10^{18} \mathrm{~cm}^{-3}\right)$ $\mathrm{Al}_{0.3} \mathrm{Ga}_{0.7} \mathrm{As}$ emitter. The band gap of the ternary material is fixed to $\mathrm{E}_{\mathrm{G}}=1.86 \mathrm{eV}$. The design difference between the AlGaAs/GaAs Pnp and the novel $\mathrm{AlGaAs} / \mathrm{In}_{0.03} \mathrm{Ga}_{0.97} \mathrm{As}_{0.99} \mathrm{~N}_{0.01}$ is the use of the quaternary material. The $\mathrm{In}_{0.03} \mathrm{Ga}_{0.97} \mathrm{As}_{0.99} \mathrm{~N}_{0.01}$ with only $1 \%$ of nitrogen incorporated in the ternary $\operatorname{In}_{0.03} \mathrm{Ga}_{0.97} \mathrm{As}$ material is lattice-matched with $\mathrm{GaAs}$ and its band gap energy is approximately $1.2 \mathrm{eV}$. The doping in the $p$-type InGaAsN collector is intentionally fixed to $2 \times 10^{17} \mathrm{~cm}^{-3}$ (that corresponds to the background doping of the best available material) with an associated thickness of $0.3 \mu \mathrm{m}$ to ensure an identical completely depleted collector. Fig. 2 shows Gummel Plots measured at room temperature for both classical and new devices. The InGaAsNbase device seems to be penalized in terms of DC current gain value with an $\beta$ value of 18 compared to 150 for the GaAs-based HBT. It shows however advantageous features for the turnon voltage $\mathrm{V}_{\mathrm{ON}}$, which is $0.2 \mathrm{~V}$ lower $(0.85 \mathrm{~V}$ compared to $1.05 \mathrm{~V})$ than the comparable 
$\mathrm{AlGaAs} / \mathrm{GaAs}$, and this makes this device very suitable for low-power consumption applications like modern portable electronics.

\section{Simulation Results}

\section{1- Material Parameters and simulation approach}

HBT operations were self-consistently simulated with the use of a drift-diffusion model by solving Poisson, carrier continuity and current density equations of a two-dimensional structure [15]. Physical models incorporated in the simulation include carrier statistics, concentration-dependent low-field mobility and generation-recombination mechanisms (Shockley-Read-Hall, optical, Auger). The geometrical design of this vertical mesa architecture exhibits an active emitter width of $3 \mu \mathrm{m}$.

The (Al,Ga)As material system has been reliably characterized for many years. The concentration-dependent minority carrier lifetime and mobility models provided by the simulator environment were used for the GaAs and AlGaAs layers. Concerning the transport properties of the quaternary material, the experimental mobility extracted from hall effect measurements shows much lower values than GaAs material with comparable doping level. A moderate 350 $\mathrm{cm}^{2} \mathrm{~V}^{-1} \mathrm{~s}^{-1} \mu_{\mathrm{n}}$ value is reported for the $n$-type InGaAsN layer $\left(\mathrm{N}_{\mathrm{D}}=3 \times 10^{18} \mathrm{~cm}^{-3}\right)$, which is about 6 times lower than typical mobility in equivalently doped GaAs. This degradation can be certainly explained by the present material quality, good enough to demonstrate working devices but not as ideal as GaAs. This material quality difference forces considering lower minority carrier lifetime $\tau_{p, n}$ for the various quaternary materials through the entire structure. A range of $\tau_{p} \sim 0.5$ $0.8 \mathrm{~ns}$ in the base has been primarily considered to adjust the experimental observation. These 
values are one order of magnitude lower than the typical lifetime value observed in $n$-type GaAs material doped in the $1-3 \times 10^{18} \mathrm{~cm}^{-3}$ range.

\section{2 - Simulation of initial experimental DC results}

The first purpose of the simulation work was to validate/modify the models and material parameters initially chosen by simulating the experimental DC performances from the two initial devices. Preliminary modeling of Pnp HBTs in the AlGaAs/GaAs materials system has been carried out to serve as reference values. Simulated results have been extracted and compared to the experimental observation, as shown in Fig. 3, with close agreement. An average current gain value of 140 associated with a turn-on voltage superior to $1.05 \mathrm{~V}$ has been directly obtained by using the general transport parameters (mobility, lifetime) provided by the simulator library. Simulations of the $P n p$ AlGaAs/InGaAsN HBT reproduce very closely the experimental Gummel plot from the first structure demonstrated using a strictly appropriate band gap energy of $1.2 \mathrm{eV}$ and adjustable mobility/lifetime values in the InGaAsN layers. Lower turn-on voltage values $(\sim 0.89 \mathrm{~V})$ associated with a $\mathrm{DC}$ current gain value of 18 at $\mathrm{V}_{\mathrm{BE}}=1.5 \mathrm{~V}$ are usually observed for the novel device.

\section{3 - Design solutions for enhanced DC current gain}

Several approaches have been considered to improve the DC performances of the Pnp InGaAsN-based device. The initial base thickness of the device was originally set to $1000 \AA$ to make the structure comparable to the conventional $\mathrm{AlGaAs} / \mathrm{GaAs}$. The current gain is generally expressed as the ratio of the minority carrier lifetime $\tau_{\mathrm{p}}$ by the transit time across the base $\tau_{\mathrm{b}}$ (which is directly proportional to the base thickness $\mathrm{X}_{\mathrm{B}}$ ). $\tau_{\mathrm{p}}$ is basically a material parameter but $\tau_{b}$ can be easily increased or reduced by modifying $X_{B}$. One way to produce higher gain is to reasonably reduce the base thickness so that more carriers can be collected instead of 
recombining. The issue of a higher epitaxial base resistivity might arise but not too excessively because sufficiently high doping concentrations can be achieved to limit the negative effect of a too resistive base layer. This would not be possible with HBT devices based on nitride materials like $\mathrm{AlGaN} / \mathrm{GaN}$ where a too thin base layer gives rise to an unacceptably high resistance due to difficulties to achieve high carrier concentration [16,17]. Fig. 4 shows the current gain versus the base-emitter voltage obtained from the initial AlGaAs/InGaAsN HBT by varying the base thickness from $1000 \AA$ down to $600 \AA$. A substantial improvement of $\beta$ up to 50 is ultimately observed by considering the thinnest base structure.

Some concerns still exist about degraded r.f. performances associated with too thin resistive base layers. One way to keep the base thick enough and producing better DC results is to enhance the base transport properties by introducing an electric field in the base. With a base electric field, the current not only flows by diffusion but also with a drift component, for an important decrease of the base transit time. Grading the aluminum or the indium content of the base layer to result in a base quasi-electric field has been previously demonstrated as an useful concept in developing high-performance HBTs [18]. Because the use of the quaternary InGaAsN material does not allow the use of energy band gap engineering, the base electric filed is here generated with a dopant-graded base. The graded donor-like doping varies in the base from $7 \times 10^{18}$ at the emitter side to $1.5 \times 10^{18} \mathrm{~cm}^{-3}$ at the collector edge for an averaged doping concentration equal to the $3 \times 10^{18} \mathrm{~cm}^{-3}$ initial one. Therefore, the sheet resistance of the graded base is similar to the base layer uniformly doped and the impact of the electric field on the transit time can be directly addressed. Significant improvement is observed compared to the non-graded structure and current gain values greater than 30 (sufficient gain level to be useful for many circuit applications) are achieved by using a moderately reduced base thickness of $800 \AA$ and the graded doping profile. 


\section{$\underline{3.4 \text { - Turn-on voltage reduction }}$}

The main advantage of employing the GaAs-lattice matched quaternary InGaAsN material is to narrow the energy band-gap (approximately $1.2 \mathrm{eV}$ ) for a lower device turn-on voltage $V_{O N}$, essential characteristic for low-power electronic applications. This has been made possible by incorporating a very small amount of nitrogen $(\sim 1 \%)$ into a ternary $\operatorname{In}_{0.03} \mathrm{Ga}_{0.97} \mathrm{As}$ alloys. The ultimate goal of this pioneering technology is to reduce even further the $V_{O N}$ voltage. Incorporating more nitrogen would allow lowering of the energy band-gap below $1.2 \mathrm{eV}$. Reports of InGaAsN-based materials lattice matched to GaAs exhibiting energy as low as $1.0 \mathrm{eV}$ have been recently published $[3,4,19]$. Although preliminary studies have indicated the increasing presence of defects with higher $\mathrm{N}$ incorporation, the simulation approach is used here to estimate the turn-on voltage characteristics the InGaAsN HBT could achieve with an energy band-gap to be as low as $1.0 \mathrm{eV}$. Transport parameters are assumed unchanged despite the higher $\mathrm{N}$ incorporation. Fig. 5 shows Gummel plots of the Pnp AlGaAs/nGaAsN HBT with several energy band gap values of the quaternary material from $1.2 \mathrm{eV}$ down to $1.0 \mathrm{eV}$. A reduction of $V_{O N}$ is systematically observed by considering lower $E_{G}$ values and a very attractive value of $0.69 \mathrm{~V}$ is ultimately predicted. The inset represents the current gain as a function of the baseemitter voltage. Unlike the turn-on voltage behavior that is probably well predicted, the lack of degradation of the maximum current gain value might not be too realistic since lower mobility and lifetime features are expected to take place with increasing amount of nitrogen. In a first approximation, these predictions could symbolize the DC properties the Pnp HBT with a band gap energy of $E_{\mathrm{G}}=1.0 \mathrm{eV}$ could have by using the material quality achieved at $1.2 \mathrm{eV}$.

\section{5 - High-frequency characteristics}

In addition to DC performances, the high frequency capabilities of the Pnp InGaAsNbased device are investigated. The unilateral power gain $U$ and the small-signal gain $h 21$ are 
calculated as a function of the frequency and their associated maximum oscillation frequency $f_{M A X}$ and cut-off frequency $f_{T}$ are extracted as figures of merits. Recently, there have been reports of GaAs-based Pnp transistors operating at microwave frequencies as high as $30 \mathrm{GHz}[20,21]$. The Pnp AlGaAs/GaAs device fabricated here to serve as references exhibits experimental $f_{T}$ and $f_{M A X}$ values in the $12-15 \mathrm{GHz}$ range. These numbers are very acceptable for the structure and processing technique chosen. The numerical approach to predict HF characteristics agrees well with the experimental observation of the AlGaAs/GaAs HBT device, as shown in Fig. 6. No high frequency characteristics have been reported on Pnp InGaAsN-based HBTs. Lower values are expected because of the less advantageous transport parameters induced by the nitrogen incorporation. Preliminary $f_{T}$ and $f_{M A X}$ values of respectively 6 and $4 \mathrm{GHz}$ achieved on this initial device from simulation are somewhat lower than in similarly designed $\mathrm{AlGaAs} / \mathrm{GaAs}$ transistors, most likely due to reduced lifetime/mobility values and a resulting higher resistivity in the base layer. The bias conditions are chosen such as the collector layer is almost completely depleted to reduce the parasitic capacitance and epitaxial resistance at the collector side. The cut-off frequency is always found to be higher than the maximum oscillation frequency probably because of a base resistivity higher than expected due to non-optimized mobility compared to GaAs. The design choice to improve transistor performances depends on whether the overall objective is to maximize $f_{T}$ or $f_{M A X}$, or optimize both. According to the classical expression of the maximum oscillation frequency, maximizing the $f_{M A X}$ value is possible with regard to $f_{T}$. The cutoff frequency is affected by the base design mainly through the base transit time. HF performance simulations have been undertaken with several base thickness values in order to maximize $f_{T}$ and analyze the corresponding $f_{M A X}$ behavior. For clarity, an identical collector-base bias is chosen and the base-emitter bias is adjusted to conserve the same collector output current during the analysis. As shown in Fig. 7, the $f_{T}$ value increases continuously (and ultimately 
reaches $16 \mathrm{GHz}$ with a $500 \AA$ base) as the base thickness is reduced due to a lower transit time across the base. The $f_{M A X}$ increases as well but much slowly and saturates when the base thickness is less than $600 \AA$. If the base is made too thin, no improvement on $f_{M A X}$ is achieved because the too high base resistance value more than compensates the influence of a higher $f_{T}$ value. Considering this threshold base thickness value of $600 \AA$, further enhancement of the base transport is expected with the use of dopant-graded base. Fig. 6 shows predicted performances obtained with the previous graded profile (see section 3.4 ) and the "optimized" base thickness. Greater $f_{T}$ and $f_{M A X}$ as well as high power gain valued ( $U>25 \mathrm{~dB}$ at high frequency) are found to be very comparable with HF characteristics observed from the Pnp AlGaAs/GaAs HBT.

\section{6 - Effect of a double Heterojunction Bipolar Transistor}

The replacement of the InGaAsN collector by GaAs forming a $\mathrm{AlGaAs} / \mathrm{InGaAsN} / \mathrm{GaAs}$ double heterostructure bipolar transistor (DHBT) is finally reported. Some advantages of using the DHBT instead of the HBT include increasing the breakdown voltage. More advantageous perhaps in this present case is the absence of a base-collector spike that usually occurs in DHBTs due to the use of a wider energy band gap material not only for the emitter but also for the collector. A very suitable conduction band-offset of $\mathrm{Q}_{\mathrm{C}}=0.92$ is commonly accepted to describe the band gap energy difference that exists between the quaternary material and GaAs at the second interface [14]. An almost perfectly aligned valence band configuration is expected to not interfere with the hole transport. Consequently, no additional design artifact like alloy composition grading or chirped superlattice is required to circumvent the traditionally problematic band alignment of DHBT transistors. The calculated DC current gain of the initial Pnp HBT device is compared in Fig. 8 with the double PnP HBT whose design only differs by the GaAs nature of its collector layer and a doping concentration of $3 \times 10^{16} \mathrm{~cm}^{-3}$ (instead of a higher $\mathrm{N}_{\mathrm{C}}=2 \times 10^{17} \mathrm{~cm}^{-3}$ for the single HBT). The energy band gap of the base is fixed to its initial 
$1.2 \mathrm{eV}$ value. An equivalent $\sim 0.89 \mathrm{~V}$ turn-on voltage is observed while the $\mathrm{DC}$ current gain value happens to be very comparable with the HBT. This agrees very well with preliminary experimental observations demonstrating the same DC behavior of the DHBT over the HBT device [22]. These performances are related to the negligible Valence Band offset $\left(\Delta \mathrm{E}_{\mathrm{V}}=0.08\right.$ $\mathrm{eV}$ ) at the base/collector interface. Note that comparing DC performances from the HBT and the DHBT structure can turn into an interesting way to confirm the band-offset ratio between InGaAsN and GaAs. The $\mathrm{Q}_{\mathrm{C}}$ value at base/collector has been varied over a wide range (from 0.6 to 0.95 ) and the best agreement between experimental observations and simulation results is obtained with a Conduction band offset ratio value of $Q_{C}=0.89 \pm 0.02$. High frequency performances have been finally investigated. The unilateral power gain $U$ of the two devices is displayed in Fig.8. The large improvement of $f_{M A X}$ from 4 to $7 \mathrm{GHz}$ is attributed to the lower collector doping that induces a more depleted collector for the DHBT at equivalent operating bias conditions for less unfavorable overall (intrinsic and extrinsic) collector capacitance. The $f_{T}$ value of the DHBT (not displayed on the graph) slightly improves to $>6 \mathrm{GHz}$. Preliminary results on DHBT devices using a dopant-graded base layer show very promising r.f. performances.

\section{Conclusion}

In summary, performances of novel Pnp InGaAsN-based heterojunction bipolar transistors have been investigated with the use of two-dimensional device simulator in order to assess their DC and r.f. capabilities for complementary HBT technology. Simulation results of the Pnp AlGaAs/InGaAsN HBT, characterized by a quaternary band-gap energy of $1.2 \mathrm{eV}$, reproduce the Gummel plot experimentally observed with a current gain $\beta$ of 18 and an advantageous turn-on voltage $\mathrm{V}_{\mathrm{ON}}$ of $\sim 0.89 \mathrm{~V}$. Improved $\mathrm{DC}$ current gain are reported by 
reasonably reducing the base thickness and introducing an electric field in the base layer, for resulting $\beta$ values as high as 50 very useful for many circuits applications. Preliminary r.f. performances indicate that the Pnp InGaAsN-based device with an appropriate base design (optimized thickness and electric field values) will demonstrate high frequency characteristics very comparable (within the $10-15 \mathrm{GHz}$ range) to the ones already reported for the conventional Pnp AlGaAs/GaAs system. In order to further lower the turn-on voltage of the device, simulations with quaternary band-gap energy as narrow as $1.0 \mathrm{eV}$ exhibit $\mathrm{V}_{\mathrm{ON}}$ values $<0.7 \mathrm{~V}$, which is $0.2 \mathrm{~V}$ lower than the initial InGaAsN-based HBT. The use of an AlGaAs/InGaAsN/GaAs PnP DHBT structure is finally highlighted. The advantageous alignment of the Valence Band (almost flat configuration at the base/collector interface with no additional junction spike features) allows achieving comparable DC performances for the DHBT device with abrupt interface. In addition, a substantial improvement of the maximum oscillation frequency $\mathrm{f}_{\mathrm{MAX}}$ is reported with the InGaAsN-based DHBT due to a more depleted collector for the DHBT at equivalent operating bias conditions for less undesirable GaAs collector capacitance. The experimental use of some of the design solutions presented here has been recently successfully demonstrated and results will be detailed in an upcoming publication. These encouraging performances on Pnp devices demonstrate the feasibility of integration for future complementary low-power applications using InGaAsN-based HBT technology.

\section{Acknowledgments}

Sandia is a multi-program laboratory operated by Sandia Corporation, a Lockheed-Martin company, for the US Department of Energy under Contract $N^{\circ}$ DE-AC04-94-AL-85000. 


\section{References}

[1] Sakai S., Ueta Y., and Terauchi Y., Jpn. J. Appl. Phys. Part 1 1993, 32: 4413-4417.

[2] Kondow M., Uomi K., Niwa A., Kitatani T., Watahiki S., and Yazawa Y., Jpn. J. appl. Phys. Part 1 1996, 35: 1273-1275.

[3] Yang X., Heroux J. B., Jurkovic M. J., and Wang W. I., Appl. Phys. Lett. 2000, 76: 795-797.

[4] Li N. Y., Hains C. P., Yang K., Lu J., Cheng I., and Li P. W., Appl. Phys. Lett. 1999, 75: 1051-1053.

[5] Kurtz S. R., Allerman A. A., Jones E. D., Gee J. M., Banas J. J., and Hammons B. E., Appl. Phys. Lett. 1999, 74: 729-731.

[6] Ito H., Yamahata S., Shigekawa N., and Kurishima K., Jpn. J. Appl. Phys. Part 1 1997, 35: 6139-6144.

[7] Chang P. C., Baca A. G., Li N. Y., Xie X. M., Hou H. Q., Armour E., Appl. Phys. Lett. 2000, 76: $2262-2264$.

[8] Sawdai D., and Pavlidis D., IEEE Trans. Microwave Theory Tech. 1999, 47: 1439-1448.

[9] Hill D. G., Tserng H. Q., and Kim T. S., Electron. Lett. 1994, 30: 597-598.

[10] Chang P. C., Baca A. G., Li N. Y., Sharps P. R., Hou H. Q., LaRoche J. R., and Ren F., Appl. Phys. Lett. 2000, 76: 2788-2790.

[11] Datta S., Shi S., Roenker K. P., Cahay M. M., and Stanchina W. E., IEEE Trans. Electron. Devices 1998, 45: 1634-1643.

[12] Ekbote S., Cahay M., Roenker K., and Kumar T., J. Appl. Phys. 1999, 86: 7065-7070.

[13] Monier C., Pearton S. J., Chang P. C., Baca A. G., and Ren F., Appl. Phys. Lett. 2000, 76: 3115-3117.

[14] Kondow M., Kitatani T., Larson M. C., Nakahara K., Uomi K., and Inoue H., J. Cryst. Growth 1998, 188: 255-259.

[15] Atlas, Silvaco International, Santa Clara, CA (1997).

[16] McCarthy L. S., Kozodoy P., Rodwell M. J. W., DenBaars S. P., and Mishra U. K., IEEE Electron Device Lett. 1999, 20: 277-279.

[17] Ren F., Abernathy C. R., Van Hove J. M., Chow P. P., Hickman R., Klaassen J. J., Kopf R. F., Cho H., Jung K. B., Laroche J. R., Wilson R. G., Hain J., Shul R. J., Baca A. G., and Pearton S. J., MRS Internet J. Nitride Semicond. 1998, Res. 3, 41.

[18] Datta S., Roenker K. P., and Cahay M. M., J. Appl. Phys. 1998, 83: 8036-8045. 
[19] Xin H. P., and Tu C. W., Appl. Phys. Lett. 1998, 72: 2442-2444.

[20] Slater D. B., Enquist P. M., Hutchby J. A., Morris A. S., and Trew R. J., IEEE Electron Device Lett. 1994, 15: 91-93.

[21] Lunardi L. M., Chandrasekhar S., and Hamm R. A., IEEE Electron Device Lett. 1993, 14: 19-21.

[22] Chang P. C., Baca A. G., Li N. Y., Hou H. Q., LaRoche J. R., and Ren F., in Proceedings of the State of the Art Programs on Compound Semiconductors XXXII, edited by R. F. Kopf, A. G. Baca, and S. N. G. Chu (The Electrochemical Society, Pennington, NJ, 2000), 305-312. 


\section{Figure Captions}

Fig. 1: Band alignment of the AlGaAs/InGaAsN heterostructure representing the emitter/base interface of the Pnp HBT.

Fig. 2: The inset displays the experimental DC results observed from the initial $A l G a A s / G a A s$ and AlGaAs/InGaAsN Pnp HBTs with almost identical epitaxial design.

Fig. 3: Simulated Gummel plots from a conventional $P n p$ AlGaAs/GaAs $H B T$ and an $\mathrm{AlGaAs} / \mathrm{InGaAsN}$ HBT. The band-gap of InGaAsN in the base an collector layers is fixed to $1.2 \mathrm{eV}$.

Fig. 4: Improvement of the calculated DC current gain $\beta$ from the initial 17 up to $\sim 50$ with the use of proper thickness and dopant-graded in the base layer.

Fig. 5: Influence of the energy band gap $\mathrm{E}_{\mathrm{G}}$ characterizing the InGaAsN material on the DC performances. A turn-on voltage of $0.7 \mathrm{~V}$ is theoretically obtainable with $E_{\mathrm{G}}$ as low as $1.0 \mathrm{eV}$. The inset shows the $D C$ current gain associated with the set of $E_{\mathrm{G} \text { InGaAsN }}$ range $\left(1.0 \mathrm{eV}<\mathrm{E}_{\mathrm{G}}<1.2 \mathrm{eV}\right)$.

Fig. 6: Small-signal performances ( $f_{T}$ from 4 up to $10 \mathrm{GHz}$ ) by considering various $P n p$ InGaAsN HBT designs in the base.

Fig. 7: Cut-off frequency $f_{T}$ and maximum oscillation frequency $f_{M A X}$ extracted from the simulation of r.f performances of Pnp InGaAsN-based HBTs as a function of the base thickness $\mathrm{X}_{\mathrm{B}}$.

Fig. 8: Differences observed on simulated DC (8.a) and rf (8.b) performances of a typical Pnp structure by replacing the InGaAsN collector (HBT) with a GaAs collector (DHBT). The general improvement is attributed to the advantageous $\mathrm{B} / \mathrm{C}$ Valence Band discontinuity $\left(\mathrm{Q}_{\mathrm{v}}=0.08\right)$. 


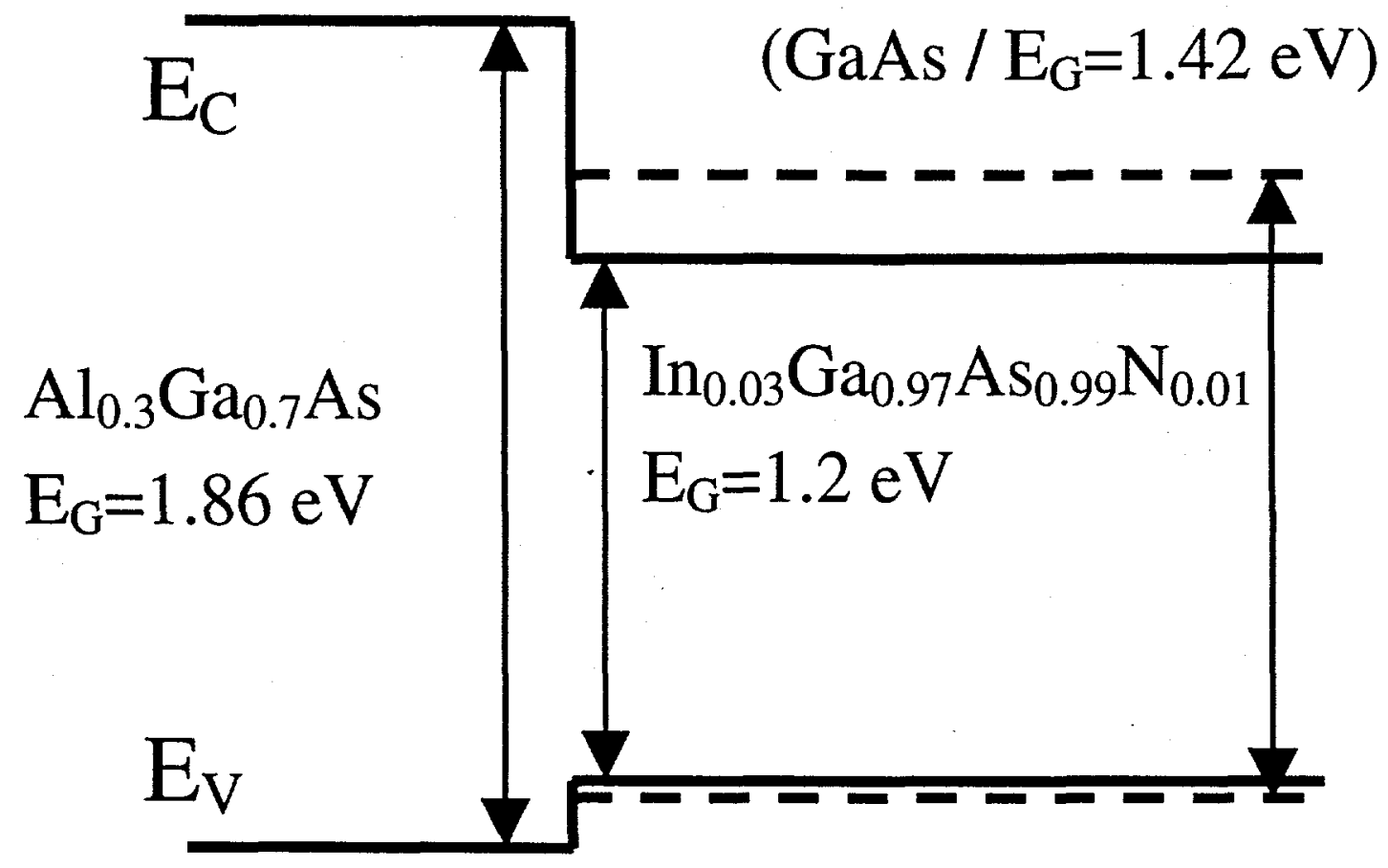

Fig. 1 


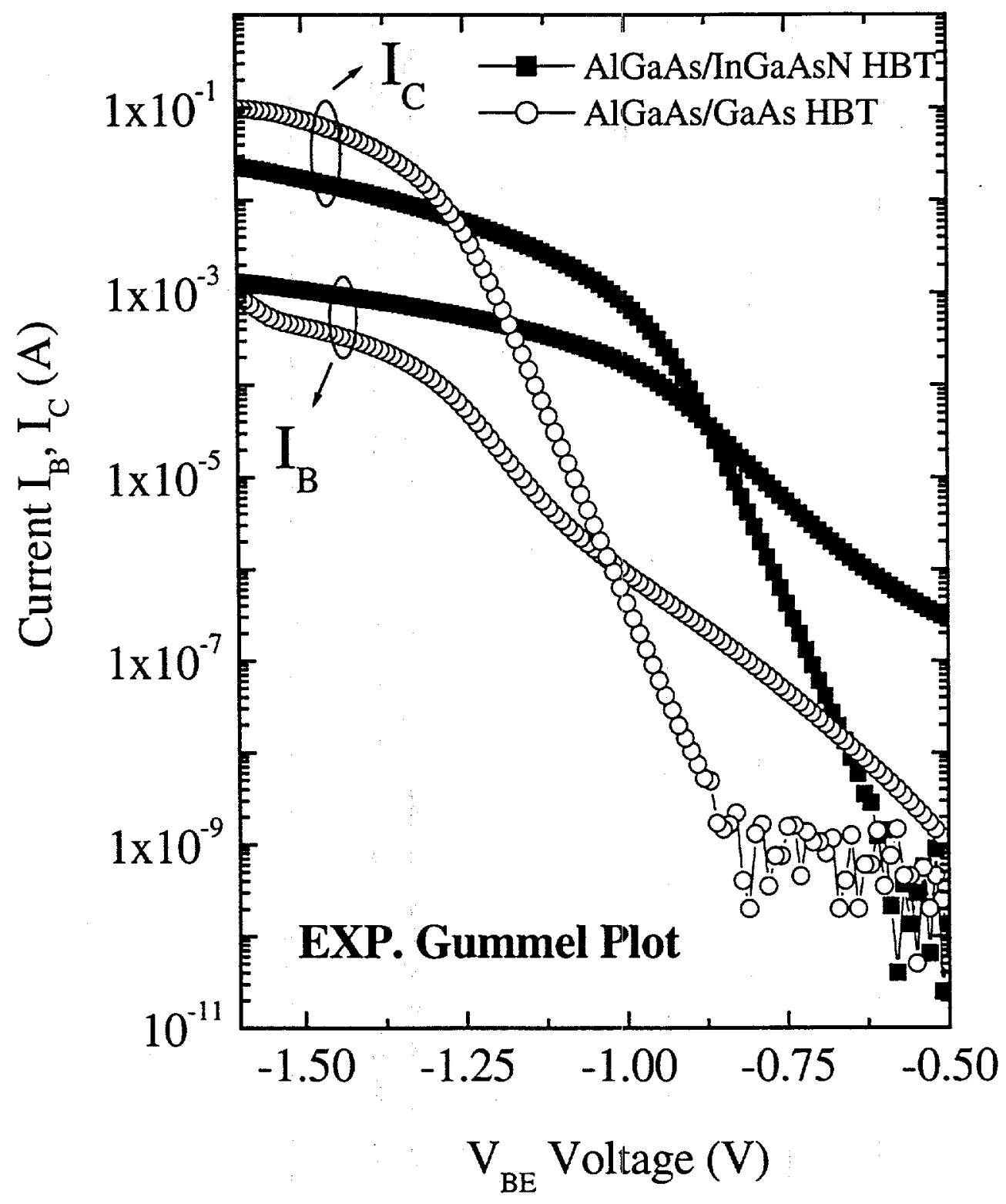

Fig. 2 


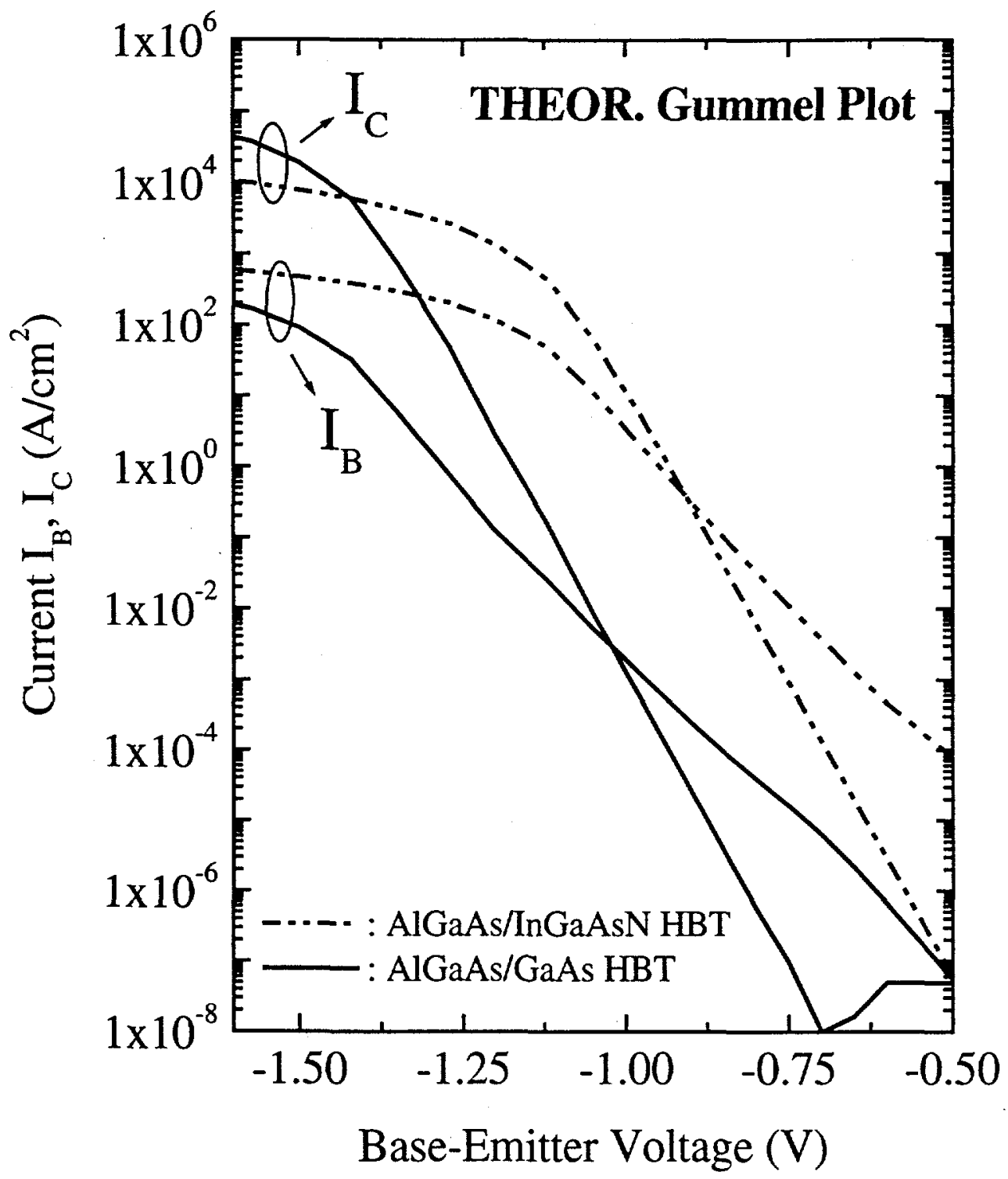

Fig. 3 


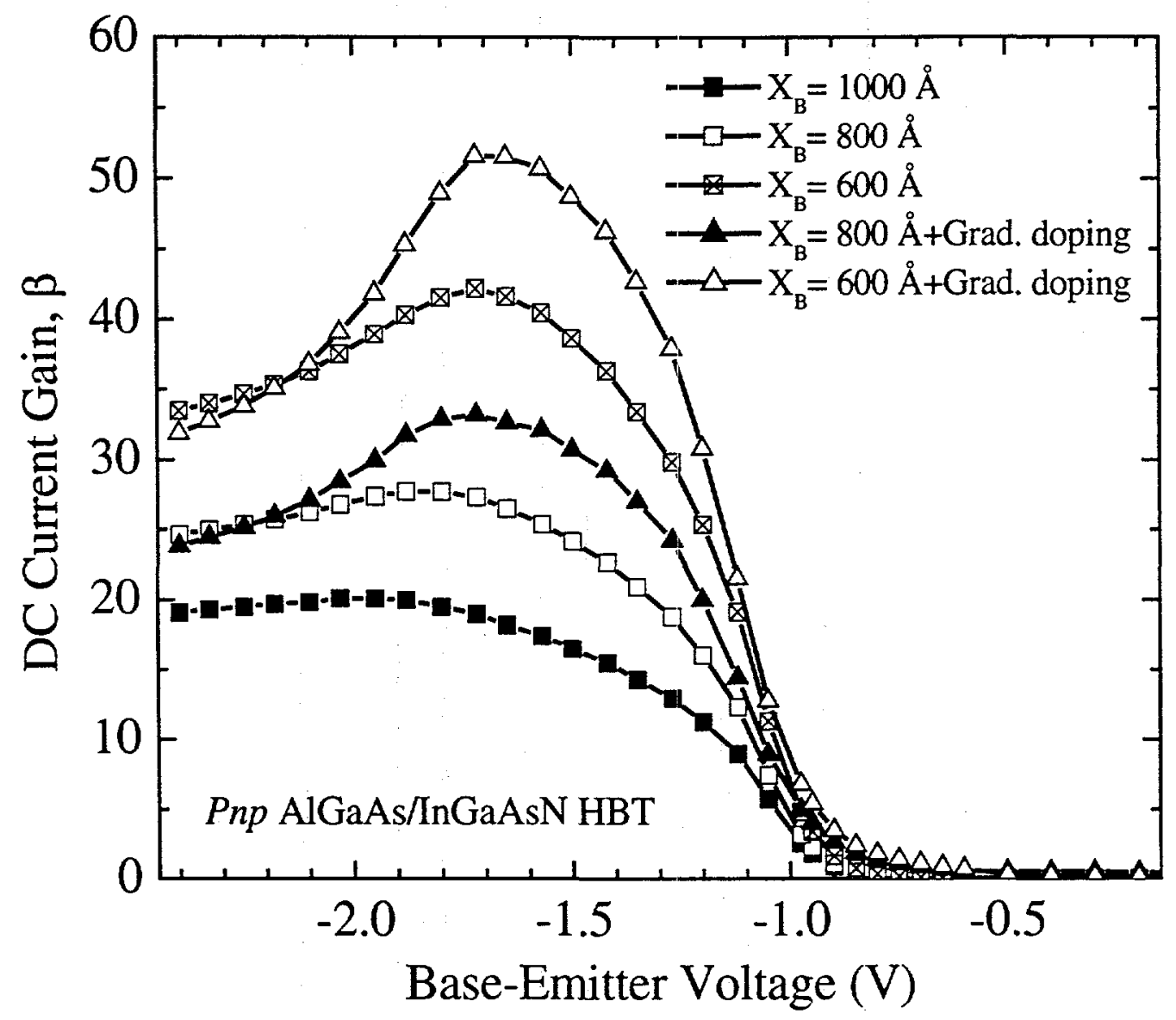

Fig. 4 


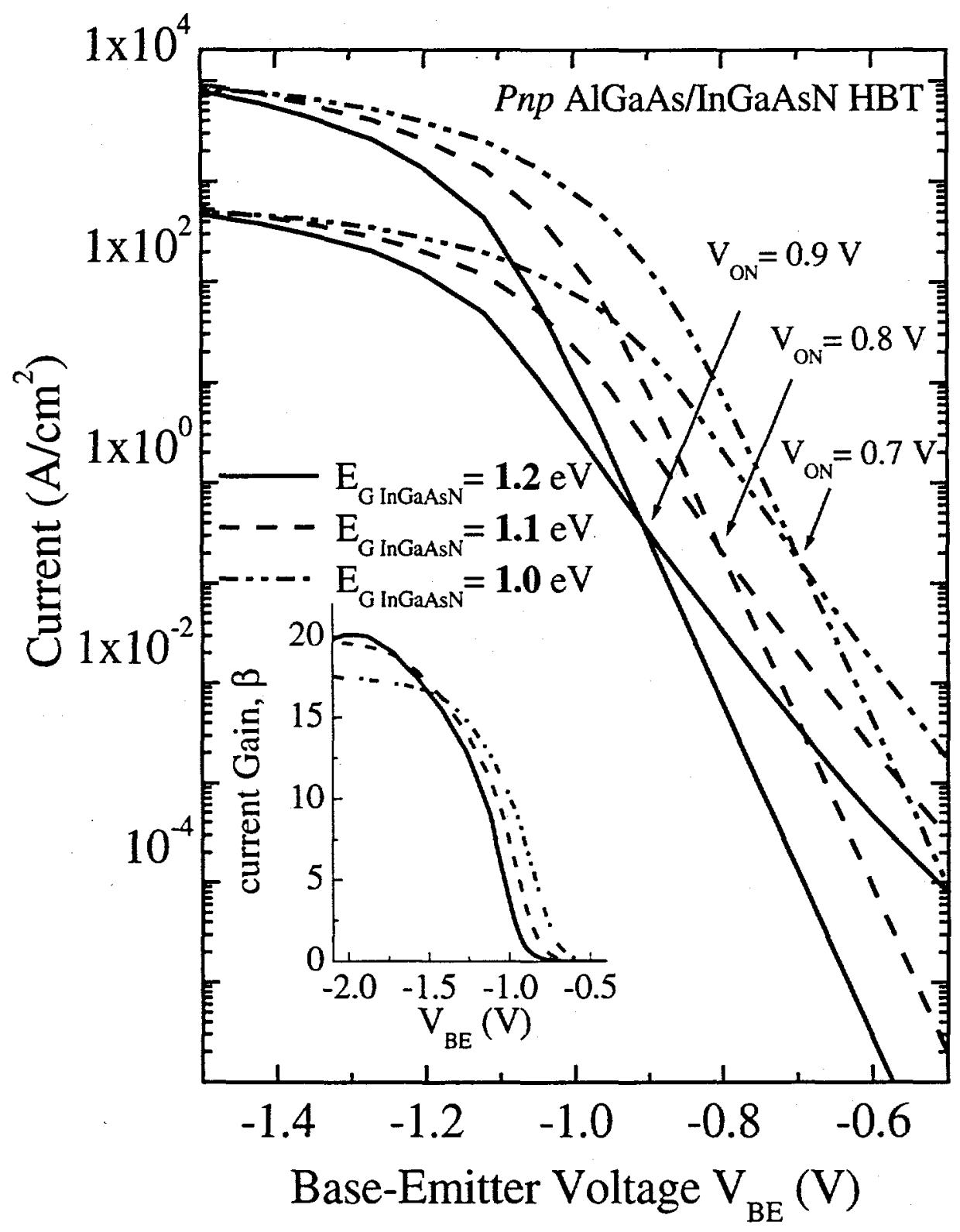

Fig. 5 


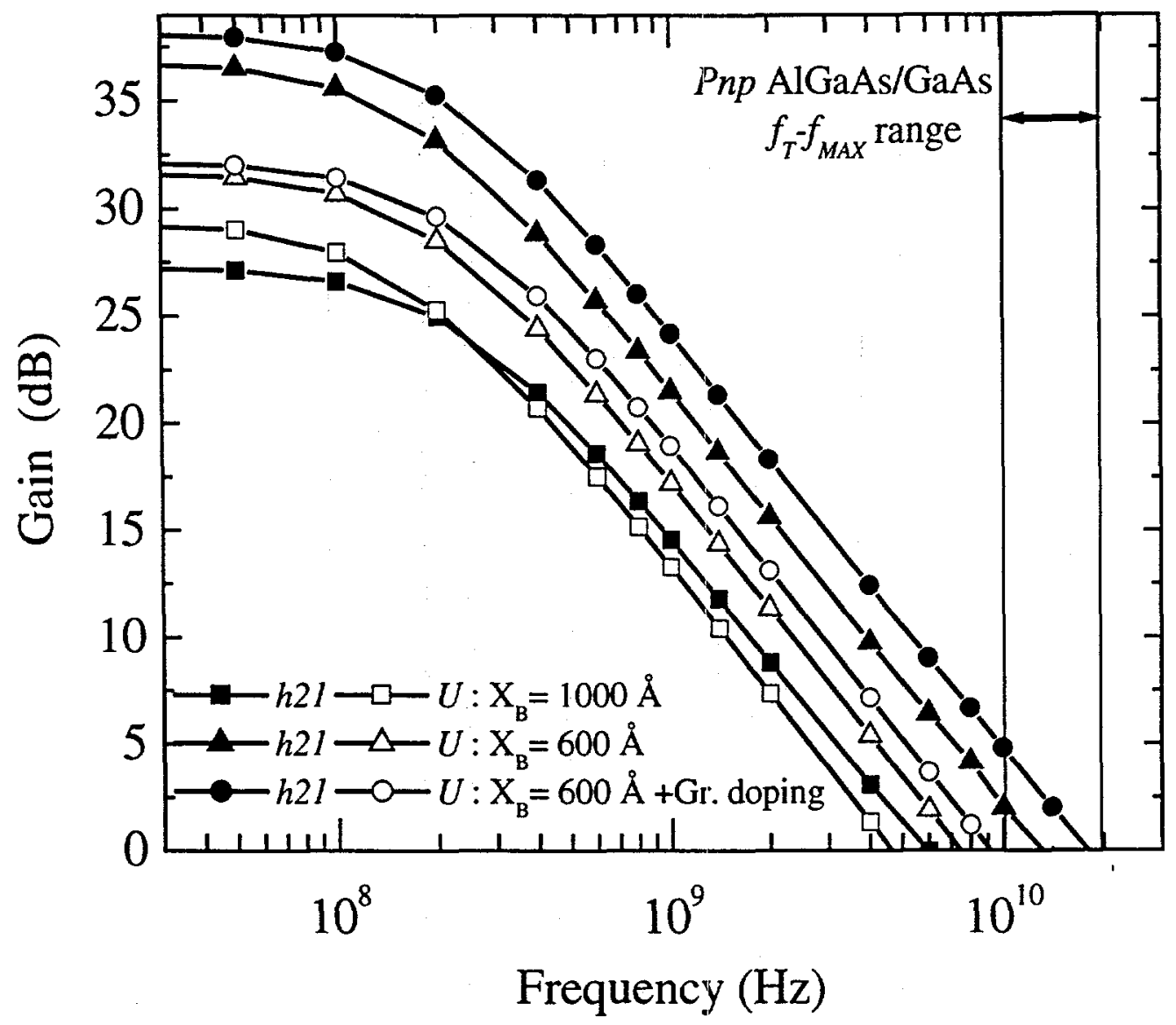

Fig. 6 


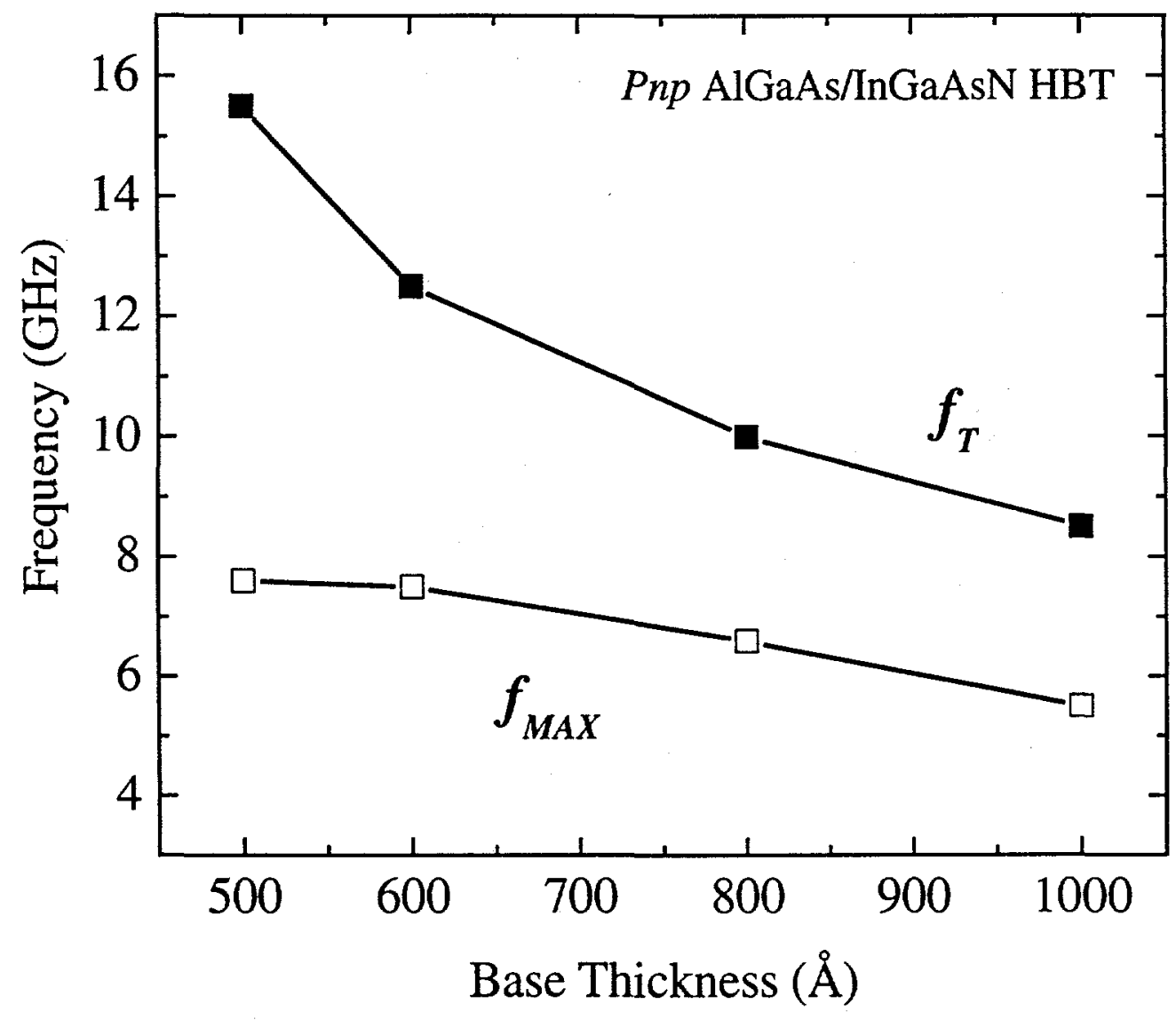

Fig. 7 

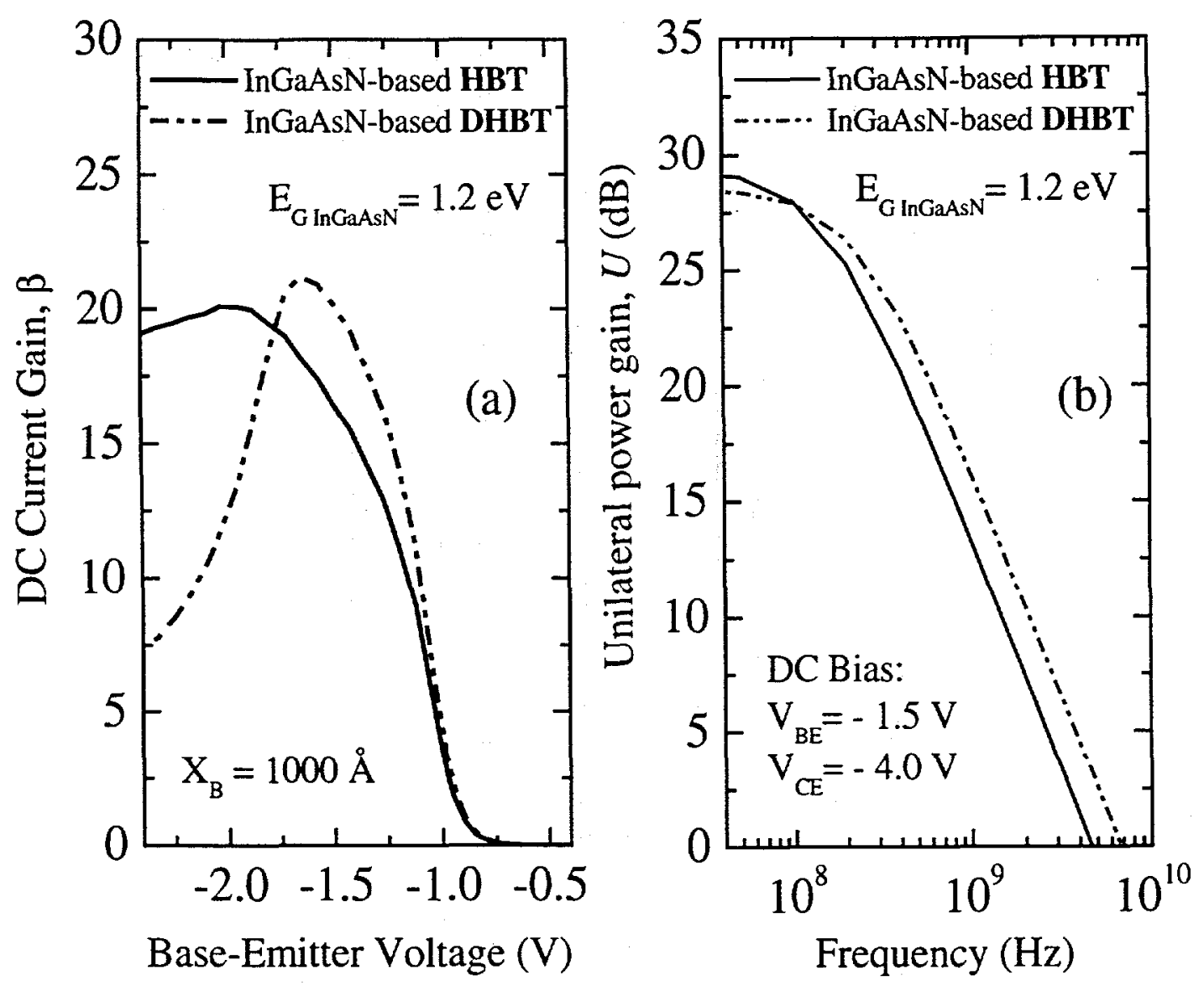

Fig. 8 